\title{
Effects of vitamin D supplementation on pulmonary function in postmenopausal women following an aquatic exercise program
}

Rodrigo Nolasco', Linda D. F. Moreira', Danilo S. Bocalini², Fernanda C. A. O. Fronza ${ }^{3}$, Rosangela Villa Marin', Marise Lazaretti-Castro'

${ }^{1}$ Departamento de Medicina, Disciplina de Endocrinologia, Faculdade de Medicina Universidade Federal de São Paulo (Unifesp/EPM), São Paulo, SP, Brasil ${ }^{2}$ Fisiologia Translacional, Programa de Pós-Graduação em Educação Física e Ciências do Envelhecimento, Universidade São Judas Tadeu (USJT), São Paulo, SP, Brasil ${ }^{3}$ Escola de Educação Física e Esporte da Universidade de São Paulo (EEFE/USP), São Paulo, SP, Brasil

\section{Correspondence to:} Rodrigo Nolasco

Ambulatório de Endocrinologia Universidade Federal de São Paulo Rua Borges Lagoa, 800 04038-030 - São Paulo, SP, Brasi rodrigonolasco@yahoo.com.br

Received on Jan/12/2016 Accepted on Jun/7/2016

\begin{abstract}
Objective: This study sought to investigate the effects of vitamin D supplementation and aquatic exercise on pulmonary function in postmenopausal women. Materials and methods: This prospective and controlled study included 104 women ( $62 \pm 6.5$ years) divided into three groups: a control group lacking vitamin $D$ and calcium supplementation which remained sedentary (CG; $n=17$ ); a control group receiving vitamin $D$ and calcium supplementation which remained sedentary $(C D G, n=33)$; and a group that completed aquatic exercises three times a week and received vitamin $D$ and calcium supplementation (DTG, $n=54$ ). Data before and after 6 months of the study were analyzed, including serum 25-hydroxyvitamin $\mathrm{D}(25(\mathrm{OH}) \mathrm{D})$ and calcium concentrations, peak expiratory flow (PEF), forced vital capacity (FVC), and cirtometry. Results: We observed significant increases in $25(\mathrm{OH}) \mathrm{D}$ concentrations in CDG $(52.9 \pm 2.4$ to $69.1 \pm 2.2 ; \mathrm{nmol} / \mathrm{L} ; \mathrm{p}<0.0001)$ and DTG groups $(55.5 \pm 3$ to $71.5 \pm$ $3 \mathrm{nmol} / \mathrm{L} ; \mathrm{p}<0.0001)$. PEF increased by $7 \pm 2 \%(p=0.0080)$ in CDG group and $11 \pm 2 \%(p<0.0001)$ in DTG group, whereas FVC increased by $7 \pm 2 \%(p=0.0016)$ in the CDG group and $10 \pm 2 \%(p<0.0001)$ in the DTG group, whereas CG had no changes in any of these parameters. The increment value of cirtometry in DTG group $(+43 \pm 3 \%)$ were significantly $(p<0.0001)$ higher than those in CG $(-4 \pm 8 \%)$ and CDG $(+4 \pm 9 \%)$ groups. Conclusion: Our data suggest that vitamin $D$ supplementation improves pulmonary function parameters in postmenopausal women. Arch Endocrinol Metab. 2017;61(1):28-35
\end{abstract}

Keywords

Spirometry; cirtometry; cholecalciferol; postmenopause

\section{INTRODUCTION}

$\mathrm{T}$ he large increase in longevity in humans during the last century raised new issues in health care, especially the control of aging-related deterioration (1). Intense efforts have been exerted to obtain new knowledge that can lead to the progression of chronic degenerative diseases and to slow the functional impairment, including deterioration of lung function (2). Vitamin D and calcium are among the potential factors related to maintaining bone and muscle health, and they cannot be separated from osteoporosis prevention in postmenopausal women. Vitamin D produced in the skin via the action of sunlight is converted into calcitriol, a potent hormone, which is important for health. Although its most common effects are on bone metabolism and mineral homeostasis, its receptors have been identified in almost all tissues, suggesting that it might have other roles $(3,4)$.

Lung function also appears to be influenced by vitamin D concentrations, with cross-sectional studies identifying associations of lower plasma concentrations of 25-hydroxyvitamin $\mathrm{D}(25(\mathrm{OH}) \mathrm{D})$ with worse lung function parameters $(5,6)$. During aging, a gradual decline in the respiratory system occurs, the related factors of which include increased lung compliance, a decreased number of alveoli, and respiratory muscle weakening, as well as rib cage deformities caused by increased thoracic kyphosis because of, among others, vertebral fractures (2). 
Different regular physical activities, including water aerobics, have been used to preserve cardiorespiratory and musculoskeletal functions during aging (7). Moreover, research showed that the treatment of vitamin $\mathrm{D}$ deficiency in menopausal women can confer musculoskeletal benefits and reduce fall and vertebral fracture rates $(8,9)$. In addition, aquatic exercise studies have also identified beneficial effects on pulmonary function in elderly women $(10,11)$.

While conducting a protocol to test the effects of a differentiated water aerobics program (HydrOS), an opportunity arose to investigate the effects of vitamin D supplementation alone or in combination with highintensity aquatic exercises on pulmonary function in postmenopausal women.

\section{MATERIAL AND METHODS}

\section{Subjects}

This was a post hoc analysis of a protocol designed to evaluate the effects of a high-intensity water aerobics program (HydrOS) in postmenopausal women (12). The initial study population consisted of women living in the city of Barueri, São Paulo who were previously sedentary and attending a service center for the elderly (Parque da Maturidade de Barueri) and who were selected from volunteers willing to participate in the study according to the following inclusion criteria: postmenopausal for $\geq 5$ years, non-institutionalized, and able to understand and respond to commands during the physical and cognitive tests. The exclusion criteria were: any physical conditions that might affect their performance in the physical tests (hypothyroidism, primary hyperparathyroidism, severe osteoarthritis, rheumatic arthritis, edema or ulcer in the lower limbs); chronic kidney disease (serum creatinine $>1.4 \mathrm{mg} / \mathrm{dL}$ ); diseases that could interfere with bone quality or neuromuscular functions; recent history of hip fracture (<2 years); thyroid-stimulating hormone level $<0.05$ or $>5.5 \mu \mathrm{IU} / \mathrm{mL}$; dependence on alcohol, tobacco, or illicit drugs; currently receiving treatment with steroids, bisphosphonates, calcitonin, or vitamin D and its metabolites; use of estrogen or selective estrogen receptor modulators; use of drugs that could interfere with postural stability or vitamin D metabolism; uncontrolled high blood pressure; use of a prosthesis; regular physical activity in the last 6 months; serious heart disease; or complications during exercise stress testing that contraindicated physical activity.
The research protocol, as well as the informed consent form, was duly approved by the Ethics Committee of Unifesp (No. 1771/2008). All volunteers who agreed to participate in the study provided written consent.

\section{Design}

In this prospective and controlled trial the preselection resulted in a group of 134 previously sedentary women. Of them, 26 were excluded on the basis of the described criteria (Figure 1). The 108 remaining participants $(58.8 \pm 6.4$ years $)$ were randomly divided into two groups. The vitamin D control group (CDG, $\mathrm{n}=33$ ) was maintained without regular physical training, and the trained group (DTG, $\mathrm{n}=54$ ) participated in the HydrOS protocol over 6 months During the study period, both groups received supplementation with 1000 IU of vitamin D3 and $500 \mathrm{mg}$ of elemental calcium daily. According to the same inclusion and exclusion criteria, a control group of 17 age-matched women with similar clinical characteristics was created. This group did not receive vitamin $\mathrm{D}$ nor participate in any physical activity program during the same period. The study design and the flow of subjects can be seen in Figure 1.

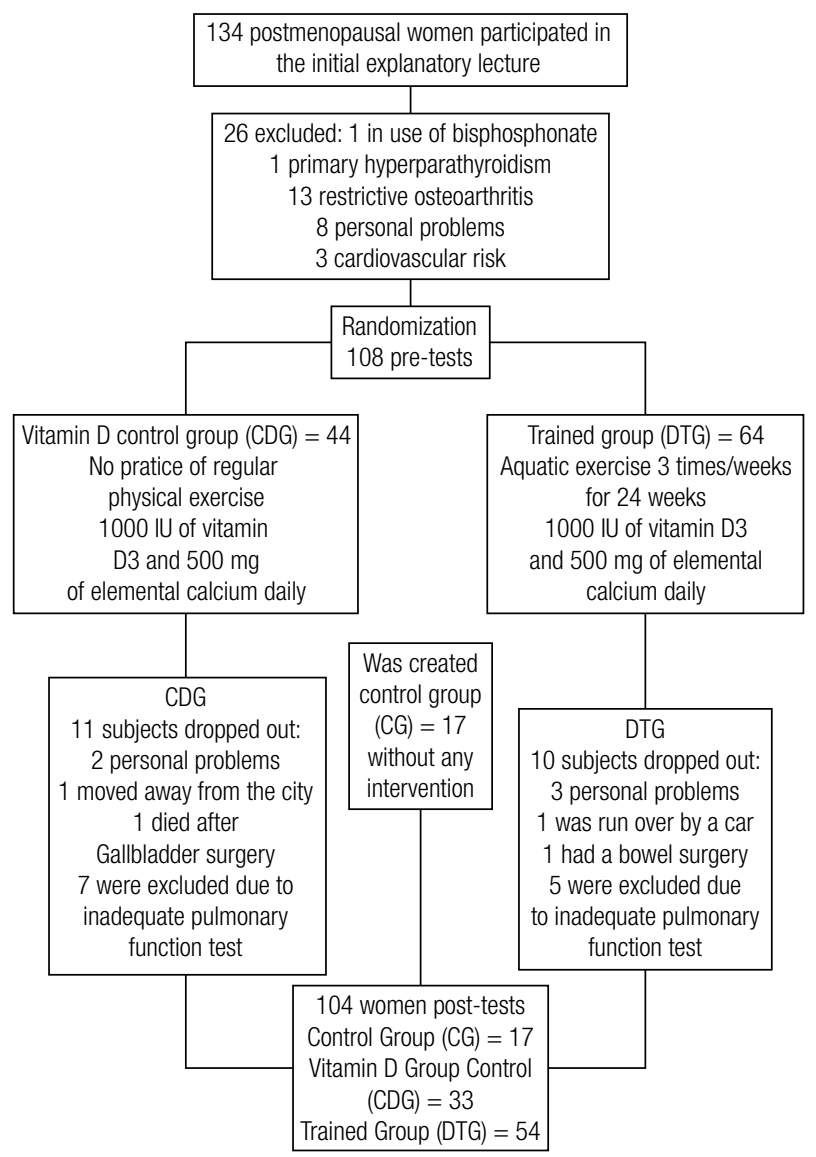

Figure 1. Flow of participants throughout the study. 
The post hoc analysis included only patients who completed the study and who met the acceptance criteria of the American Thoracic Society for the analysis of pulmonary function tests (CG, $\mathrm{n}=17$; $\mathrm{CDG}, \mathrm{n}=33$; and DTG, $\mathrm{n}=54$ ).

\section{Supplementation}

Prior to the start of the protocol, calcium intake in all groups was evaluated by a nutritionist through 24-h diet recall (13) and the daily calcium intake was similar among the groups. None of the participants received more than $600 \mathrm{mg}$ of calcium daily.

The volunteers in the control group were told to not change their lifestyle or consume any vitamin supplement during the observation period. Under medical supervision, the CDG and DTG groups received one tablet daily containing 1000 IU of cholecalciferol (vitamin D) and $500 \mathrm{mg}$ of elemental calcium (as calcium carbonate) after breakfast. The participants were instructed to maintain their usual diet. During the intervention period with supplementation, the protocol adherence rate was $94 \%(\mathrm{SD} \pm 3)$.

\section{Parameters analyzed}

The selected subjects were evaluated via anamnesis, functional capacity tests, spirometry, fasting blood collection, and bone densitometry tests to evaluate body composition. Those who did not undergo all procedures and measures or attend at least $85 \%$ of the planned sessions were excluded from the study.

\section{Total calcium and 25(OH)D}

All volunteers underwent fasting blood collection. A radioimmunoassay method (DiaSorin, Stillwater, $\mathrm{MN}$, USA) was used to determine serum $25(\mathrm{OH}) \mathrm{D}$ levels. The intra- and interassay coefficients of variation $(\mathrm{CVs})$ were 5.6 and $10 \%$, respectively. An enzymatic colorimetric method (ADVIA 1650, Bayer Ltd., Tokyo, Japan) was used to measure plasma levels of total calcium $(\mathrm{CaT})$, with intra- and interassay CVs of 1.30 and $1.95 \%$, respectively.

\section{Anamnesis and physical examination}

Medical and family history, ethnicity, diet, alcohol intake, smoking, and current medications were searched via anamnesis. The initial physical activity level of each participant was checked using the International Physi- cal Activity Questionnaire, short version, already duly validated (14).

\section{Body composition}

Total body mass $(\mathrm{kg})$ and height $(\mathrm{cm})$ were obtained using an analog scale accurate to $0.1 \mathrm{~kg}$ (Filizola model 31, Filizola, São Paulo, SP, Brazil). Body composition was examined via whole-body dual energy X-ray absorptiometry (DXA) using a densitometer with a dual emission X-ray source (Hologic Model Discovery A, Waltham, MA, USA). All procedures involving DXA were performed in the Osteometabolic Diseases Clinic of Unifesp Endocrinology Course, and the acquisition of the exams was systematically performed using the same technique and analyzed by the same examiner.

\section{Pulmonary function}

Pulmonary function was assessed by spirometry using a digital portable spirometer (One Flow; Clement Clarke International, England). Patients were previously instructed about the testing process. Each individual was positioned sitting while wearing a nose clip with her feet flat on the floor and head in a neutral and raised position. After the explanation, the subject immediately performed a maximal inspiration, followed by forced expiration with the tube placed on the tongue between the teeth and the lips clenched to prevent perioral leaks. At least six full spirometric maneuvers were performed until the difference between the latest maneuvers was $<5 \%$. The best result was employed for the analyses following the American Thoracic Society guidelines and meeting the acceptability and reproducibility criteria (15). The data were automatically transferred to an Amazon PC computer using software provided by the equipment manufacturer (ONE FLOW SOFT; Clement Clarke International, England). The following variables were considered: peak expiratory flow (PEF), forced expiratory volume in the first second of the maneuver $\left(\mathrm{FEV}_{1}\right)$, and forced vital capacity (FVC).

The chest expansion evaluation was conducted via dynamic cirtometry at the axillary level using a $1-\mathrm{cm}$ wide measuring tape in $0.5-\mathrm{cm}$ increments. The test was performed with each participant in a standing position, and the tape was placed at the axillary level around her bare chest. Each participant was instructed to perform a maximum expiration and inspiration, and the difference in centimeters between the two torso circumference values was recorded. 


\section{Exercise protocol}

The exercise sessions occurred three times a week in in a covered swimming pool with a depth of $1.20-1.40 \mathrm{~m}$ and temperature of $29-31^{\circ} \mathrm{C}$ located in Parque da Maturidade de Barueri, São Paulo. During the lessons, we asked the participants to stand in the pool so that the water was near the xiphoid process. To control the training intensity, three heart rate sensors (RS100 BLK; Polar, Finland) were used by three different students in each session so that at the end of 6 months, all participants had already used the heart rate sensor several times. In addition, the participants were taught how to use a Borg CR-10 category scale of perceived exertion (ranging from 0 - nothing at all, to 10 - very, very hard) used along with the measurement of the heart beat rate of the participants during the sessions (12).

During the lessons, we observed that the heart rate shown on the heart rate sensors was equivalent to the grade given by the participants on the Borg CR-10 scale. At every stage of the protocol, various muscle groups (chest and back, biceps and triceps, shoulders, quadriceps and posterior thigh, hip adductors and abductors, and calf and abdominals) were trained. The workout routine was gradually changed from two to five repetition sets of the same exercise, e.g., two sets of $30 \mathrm{~s}$ each, then moving on to three sets of $20 \mathrm{~s}$ each, followed by four sets of $15 \mathrm{~s}$ each, and ending with five sets of $10 \mathrm{~s}$ each. For the cardiorespiratory exercises, we used the Borg scale adapted as follows: $60 \%$ maximum heart rate (MHR), scale level 6 for 16 minutes of the session; 70\% MHR, scale level 7 for 13 minutes of the session; $80 \% \mathrm{MHR}$, scale level 8 for 9 minutes of the session; and $90 \% \mathrm{MHR}$, scale level 9 for 7 minutes of the session (12). After the 6-month intervention period with a resistance aquatic exercise program, all tests were repeated in the three groups.

\section{Statistical analysis}

For all statistical analyses, the results were considered significant at $p<0.05$. The Kolmogorov-Smirnov test was used to test data normality. The other normally distributed parameters were compared in two manners: intragroup before and after the study using Student's $t$-test for matched samples; and intergroup before and after the study using Student's $t$-test for independent samples. The chi-square test was used to verify the distribution of the different races of the 3 groups. One-way analysis of variance and Tukey's post hoc test were used when necessary to identify statistical differences.

\section{RESULTS}

Table 1 shows that the three groups were similar at baseline in terms of biometric characteristics, total calcium, and body composition. The racial distribution (white and no white) did not differ between groups ( $\mathrm{p}=0.056$ ).

After 6 months of study, serum 25(OH)D levels similarly increased in the two groups supplemented with vitamin D3 $(\mathrm{p}<0.001)$. The mean value in the CDG group increased by $21 \%$ (from $52.9 \pm 2.4$ to $69.1 \pm 2.2 ; \mathrm{nmol} / \mathrm{L}, \mathrm{p}<0.0001)$, in the DTG group increased by $23 \%$ (from $55.5 \pm 3$ to $71.5 \pm 3$ for 3 $\mathrm{nmol} / \mathrm{L}, \mathrm{p}<0.0001$ ), and in the CG group did not change significantly (from $50.1 \pm 2.6$ to $49.82 \pm 2.4$ $\mathrm{nmol} / \mathrm{L}, \mathrm{p}=0.4605$ ) (Figure 2).

Table 1. Clinical features and anthropometric characteristics of the three groups at baseline and study completion

\begin{tabular}{|c|c|c|c|c|c|c|c|c|c|}
\hline \multirow{2}{*}{ Variable } & \multicolumn{3}{|c|}{ Control Group $(n=17)$} & \multicolumn{3}{|c|}{ Vitamin D Group ( $\mathrm{n}=33$ ) } & \multicolumn{3}{|c|}{ Trained Group $(n=54)$} \\
\hline & Before & After & $\%$ & Before & After & $\%$ & Before & After & $\%$ \\
\hline Age & $59.9 \pm 2$ & & & $58 \pm 0.8$ & & & $59 \pm 6$ & & \\
\hline Weight (kg) & $70 \pm 3$ & $70 \pm 3$ & $0.2 \pm 0.4$ & $74 \pm 2$ & $75 \pm 3$ & $1.3 \pm 0.6$ & $73 \pm 2$ & $73 \pm 2$ & $0.7 \pm 0.4$ \\
\hline Height (cm) & $1.59 \pm 2$ & $1.59 \pm 2$ & $-0.01 \pm 0.1$ & $1.56 \pm 1$ & $1.56 \pm 1$ & $0.12 \pm 1$ & $1.56 \pm 0.1$ & $1.56 \pm 0.1$ & $0.22 \pm 0.6$ \\
\hline BMI $\left(\mathrm{kg} / \mathrm{m}^{2}\right)$ & $27 \pm 0.1$ & $27 \pm 0.1$ & $0.23 \pm 0.40$ & $30 \pm 0.7$ & $30 \pm 0.8$ & $0.87 \pm 0.51$ & $29 \pm 0.7$ & $29 \pm 0.7$ & $-0.48 \pm 0.78$ \\
\hline Fat mass (kg) & $26 \pm 1.7$ & $26 \pm 1.8$ & $-7.0 \pm 6$ & $29 \pm 1.6$ & $29 \pm 1.7$ & $-1.3 \pm 1.3$ & $28 \pm 1.1$ & $28 \pm 1.2$ & $-1.0 \pm 2$ \\
\hline Lean mass (kg) & $42 \pm 17$ & $42 \pm 16$ & $-0.5 \pm 1$ & $42 \pm 16$ & $44 \pm 12$ & $4 \pm 3$ & $43 \pm 10$ & $43 \pm 10$ & $0.8 \pm 1$ \\
\hline Fat $\%$ & $37 \pm 1.3$ & $36 \pm 1.5$ & $-1 \pm 1$ & $38 \pm 1.0$ & $38 \pm 1.1$ & $-1.5 \pm 0.8$ & $38 \pm 0.7$ & $38 \pm 0.7$ & $-1 \pm 0.8$ \\
\hline Cirtometry (cm) & $2.05 \pm 0.3$ & $2.04 \pm 0.2$ & $-4 \pm 5^{a}$ & $2.12 \pm 0.14$ & $2.45 \pm 0.16$ & $4 \pm 9^{a}$ & $2.21 \pm 0.13$ & $3.93 \pm 0.16^{*}$ & $43 \pm 3^{b}$ \\
\hline Ca T (RV: 8.5-10.5 mg/dL) & $9.23 \pm 0.43$ & $9.14 \pm 0.28$ & $-0,9 \pm 2$ & $9.50 \pm 0.23$ & $9.20 \pm 0.31$ & $-3,2 \pm 4$ & $9.61 \pm 0.33$ & $9.40 \pm 0.39$ & $-2,2 \pm 3$ \\
\hline
\end{tabular}

Values are expressed as the mean $\pm \mathrm{SE}$ of the biometric measurements and total serum calcium (CaT) levels of the control (CG), control with vitamin D and calcium supplementation (CDG), and training (DTG) groups before and after the intervention. ${ }^{*} p<0.0001$, indicate differences detected using Student's $t$-test versus before the intervention. Different letters indicate statistically significant differences $(p<0.05)$ on one-way analysis of variance (Tukey's post hoc test) in relation to the percentage change between the groups. BMI, body mass index. RV $=$ Reference values. ${ }^{\star} p<0.05$. 
There were similarly significant improvements in $\operatorname{PEF}(\mathrm{L} / \mathrm{m})$ and FVC $(\mathrm{L})$ in both groups treated with vitamin D3 (CDG and DTG) regardless of physical training, whereas changes were not observed in the CG group (Figure 3). Although $\mathrm{FEV}_{1}$ values were higher at the end of study than the baseline values in the vitamin D-supplemented groups, this change did not reach statistical significance (Figure 3 ). The measure of chest expansion (dynamic cirtometry), however, revealed a significant improvement only in the group that underwent physical training (Table 1).
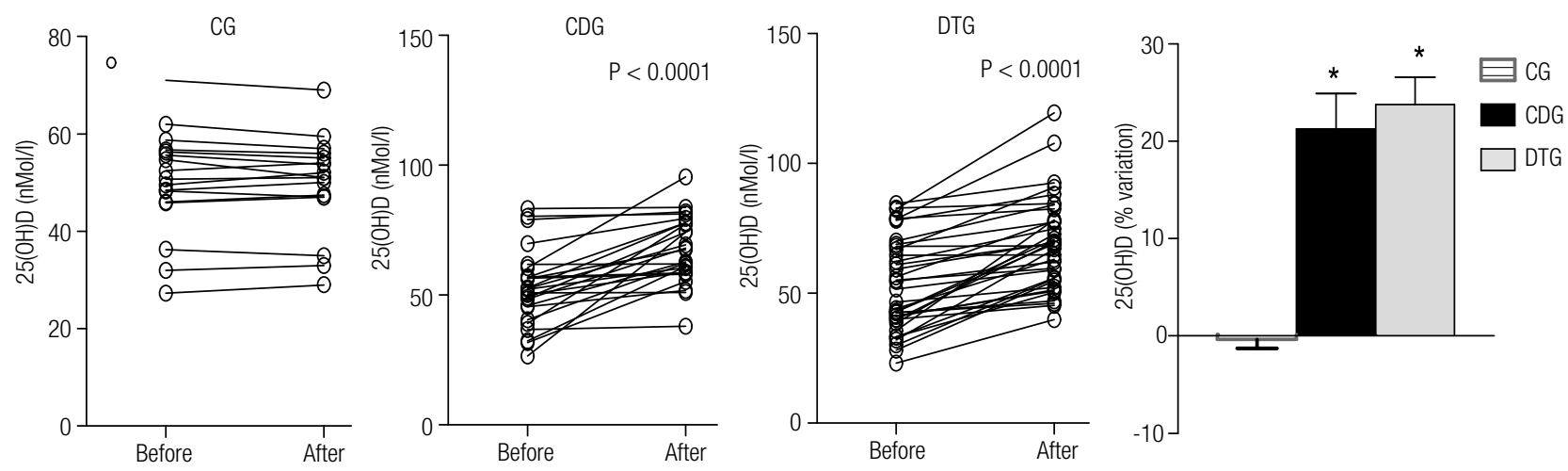

Figure 2. Evolution of serum 25-hydroxyvitamin $\mathrm{D}(25(\mathrm{OH}) \mathrm{D})$ levels. Values are expressed as the mean $\pm \mathrm{SE}$ of $25(\mathrm{OH}) \mathrm{D}$ levels in the control (CG), control with vitamin $D$ and calcium supplementation (CDG), and training (DTG) groups before and after the intervention. ${ }^{*} p<0.0001$, indicate differences detected using Student's $t$-test versus before the intervention.
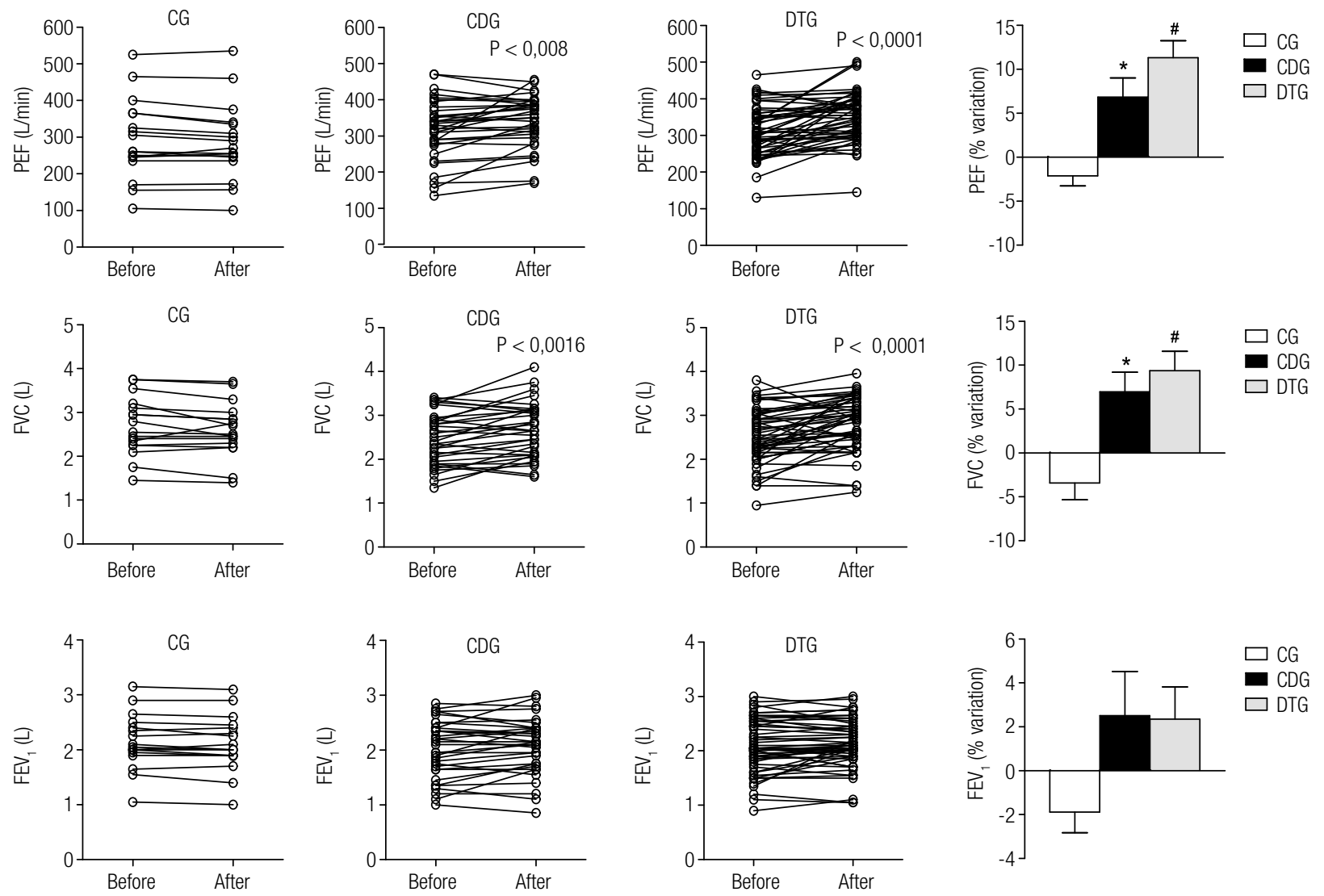

Figure 3. Evolution of pulmonary function test data during the study in the three groups. Values are expressed as the mean \pm SE and percentage change for peak expiratory flow (PEF), forced vital capacity (FVC) and forced expiratory volume in $1 \mathrm{~s} \mathrm{(FEV})_{1}$ ) in the control (CG), control with vitamin D and calcium supplementation (CDG), and training (DTG) groups before and after intervention. ${ }^{*} p<0.0001$ and $\# p<0.01$, indicate differences detected using Student's $t$-test versus before the intervention. 


\section{DISCUSSION}

This study is a by-product of a broader protocol that assessed the effects of a high-intensity water aerobics program in postmenopausal women using several physical and laboratory parameters $(12,16)$. Our results demonstrated that daily treatment with 1,000 IU of vitamin D3 for 6 months effectively produced a significant increase in plasma $25(\mathrm{OH}) \mathrm{D}$ concentrations in most of the volunteers. In our study, this increase on $25(\mathrm{OH}) \mathrm{D}$ levels was associated with an improvement in pulmonary function expiratory parameters (measure by spirometry), even in sedentary women, regardless of no participation in the aquatic exercise program. The trained group, additionally, was the only group to display improvement in the expandability parameter measured by cirtometry, suggesting some effect of water aerobics on this parameter (12). We have to point out that all volunteers had age-related normal values on spirometry at baseline, and both Vitamin D-treated groups improved similarly their expiratory parameters, not seen in the control group (CG). A possible explanation for the similar results on the pulmonary function parameters of DTG and CDG would be related to the increased respiratory muscle mass. The greater dynamic compression (restrictive) of the airways would lead to the fall of the flows measured at nozzle (17). The same dose of supplementation (1,000 IU/day) was used in another study (18) which was able to induce a significant increment on serum levels of $25(\mathrm{OH}) \mathrm{D}$ after 3 months $(+17,6 \mathrm{nmol} / \mathrm{L}$, in average $)$.

The correlations between vitamin $\mathrm{D}$ metabolism and respiratory function have been widely studied in the literature (6). However, the results are not yet conclusive (19); rather, they remain rare in prospective intervention studies, and to our knowledge, no study has examined postmenopausal women without previous lung disease. In a randomized prospective double-blind study, supplementation with vitamin D in asthmatic children reduced the risk of exacerbations triggered by acute respiratory infection and significantly improved $\mathrm{FEV}_{1}$ values (20). Another prospective study in patients with chronic obstructive pulmonary disease (COPD) and vitamin $\mathrm{D}$ deficiency observed increases in respiratory muscle strength, reductions in the degree of dyspnea, and superior physical performance after 1 year of vitamin D supplementation (21).

Several studies observed an increased prevalence of inadequate vitamin $\mathrm{D}$ levels in patients with different respiratory diseases such as asthma, COPD, tuberculosis, and a number of infections of the respiratory system (22-24). In observational studies such as the NHANES cohort, a cross-evaluation of 14,000 adults uncovered a significant association between higher $25(\mathrm{OH}) \mathrm{D}$ levels and better results for $\mathrm{FEV}_{1}$ and FVC (5). Similar results were observed by other authors in 1315 Chinese children (25). A Danish longitudinal study that followed 18,507 patients of different age groups for 20 years found that lower serum $25(\mathrm{OH}) \mathrm{D}$ concentrations were associated with worse pulmonary function and an accelerated decline in $\mathrm{FEV}_{1}$ and FVC parameters (6).

Studies have indicated that respiratory epithelial cells express $1 \alpha$-hydroxylase, which is responsible for the conversion of $25(\mathrm{OH}) \mathrm{D}$ to its biologically active form $1,25(\mathrm{OH})_{2} \mathrm{D}_{3}$, as well as the specific receptor for vitamin D (VDR) $(26,27)$. Cross-sectional and prospective studies uncovered evidence associating the actions of vitamin D with increased surfactant substance levels and reduced inflammation in the respiratory tissues via VDR expressed in the airways $(28,29)$. Besides, there is evidences for the action of vitamin $\mathrm{D}$ on the immune system, by increasing levels of LL-37 (cathelicidin), a peptide capable of promoting innate immunity and inducing the destruction of infectious agents, including Mycobacterium tuberculosis and influenza virus $(19,29,30)$.

In addition, some studies linked the actions of vitamin $\mathrm{D}$ to inhibited proliferation of metalloproteinases of the extracellular matrix (ECM) as well as the balance of type III collagen synthesis by fibroblasts (31). The ECM of lung tissue plays a key role in the structure and mechanical properties of the lungs, thus reflecting pulmonary function $(5,32)$.

Studies in rats evaluated the direct effects of vitamin $\mathrm{D}$ on lung growth, and they observed an increased lung volume and improved pulmonary function in these animals. These results were obtained by analyzing the forces generated by the elastic recoil of the lungs in rats with vitamin $\mathrm{D}$ deficiency by plethysmography and histological analysis of the lung tissue, respectively (28). Rats born to females not supplemented with vitamin D displayed structural changes, such as a significant increase in airways resistance, and changes in mesenchymal differentiation markers of the trachea compared to rats born to supplemented females (33). The direct effects of active vitamin $\mathrm{D}$ on lung tissue observed in these experimental studies could explain our findings in this population of women supplemented with vitamin $\mathrm{D}$, even in the absence of physical training (CDG group). 
The improvement observed via cirtometry only in the DTG group suggests that high-intensity aquatic exercises can increase chest expansion, probably by strengthening breathing muscles (17). This improvement may be associated with the influence of the physical properties of water, which increase voluntary breathing. The immersion of a subject in a liquid medium to the level of the xiphoid process promotes an increase of $60-65 \%$ in the work of breathing caused by increased resistance to thorax expansion produced by hydrostatic pressure and an increased blood volume in the thorax $(34,35)$. This positive effect of the aquatic environment appears to favor the process of inspiratory force, as demonstrated by some studies in healthy elderly subjects (34).

Despite these findings, this project has limitations such as the discrepancy among the sample sizes, particularly the smaller number of individuals in the control group. A fourth group without vitamin D supplementation subjected exclusively to an aquatic exercise program could be used to evaluate the isolated effects of exercise on pulmonary function. There were no surveys conducted on the time of sun exposure of the study participants. However, the samplings were performed all on the same occasions, therefore, we can suppose that the potential seasonal variations of Vitamin D were similar in the 3 groups, although we have not controlled the individual quantity of exposure to sunlight. Another limiting factor was the lack of an assessment of respiratory muscle strength through measurements of inspiratory and expiratory pressures.

In conclusion, vitamin D supplementation was associated with improved spirometric parameters in postmenopausal women independent of participation in an aquatic exercise program. Aquatic exercises in turn increased chest expansion in the trained group. Based on our findings in addition to related literature, there are strong evidences that Vitamin D can play a role on pulmonary function. The increase of Vitamin D levels could also be a supporting measure for the strategies employed for preventing and treating diseases that impair pulmonary function.

Acknowledgments: this study was supported by Fapesp (Fundação de Amparo à Pesquisa do Estado de São Paulo), grant No. 08/50179-9. We are grateful for Yeda Queiroga for their administrative assistance and The Federal Agency for Support and Evaluation of Graduate Education (Higher Education Personnel Improvement Coordination - Capes) for the financial support.

Disclosure: no potential conflict of interest relevant to this article was reported.

\section{REFERENCES}

1. Lunenfeld B, Stratton P. The clinical consequences of an ageing world and preventive strategies. Best Pract Res Clin Obstet Gynaecol. 2013;27(5):643-59.

2. Moazami M, Farahati S. The effects of aerobic training on pulmonary function in postmenopausal women. Int J Sport Std. 2013;3(2):169-74.

3. Maeda SS, Lazaretti-Castro M. Vitamina D. In: Maeda SS, Silva DMW. Guia prático em osteometabolismo. São Paulo: Segmento Farma; 2014. p. 37-51.

4. Gröber U, Spitz J, Reichrath J, Kisters K, Holick MF. Vitamin D: Update 2013: from rickets prophylaxis to general preventive healthcare. Dermato-endocrinology. 2013;5(3):331-47.

5. Black PN, Scragg R. Relationship between serum 25-hydroxyvitamin d and pulmonary function in the third national health and nutrition examination survey. Chest. 2005;128:3792-8.

6. Afzal S, Lange P, Bojesen SE, Freiberg JJ, Nordestgaard BG. Plasma 25-hydroxyvitamin D, lung function and risk of chronic obstructive pulmonary disease. Thorax. 2014;69:24-31.

7. Moreira LD, Oliveira ML, Lirani-Galvão AP, Marin-Mio RV, Santos RN, Lazaretti-Castro M. Physical exercise and osteoporosis: effects of different types of exercises on bone and physical function of postmenopausal women. Arq Bras Endocrinol Metabol. 2014;58(5):514-22.

8. Dawson-Hughes B. Serum 25-hydroxyvitamin D and functional outcomes in the Elderly. Am J Clin Nutr. 2008;88 (suppl):537S40 S.

9. Bischoff-Ferrari HA, Dawson-Hughes B, Staehelin HB, Orav JE, Stuck $A E$, Theiler $R$, et al. Fall prevention with supplemental and active forms of vitamin D: a meta-analysis of randomised controlled trials. BMJ. 2009;339:b3692.

10. Takeshima N, Rogers ME, Watanabe E. Water based exercise improves health-related aspects of fitness in older women. Med Sci Sports Exerc. 2002;33:544-51.

11. Vedana TA, Santos RN, Pereira JM, Araujo SP, Portes Júnior MP, Portes LA. Influência da hidroginástica sobre a composição corporal, aspectos cardiovasculares, hematológicos, função pulmonar e aptidão física de adultos e idosos. Braz J Biomotricity. 2011;5(2):65-79.

12. Moreira LDF, Fronza FC, Dos Santos RN, Teixeira LR, Kruel LF, Castro ML. High-intensity aquatic exercises (HydrOS) improve physical function and reduce falls among postmenopausal women. Menopause. 2013;20(10):1012-9.

13. Buzzard M. 24-hours dietary recall and food record methods. In: Willett WC. Nutritional Epidemiology. 2nd.ed. Oxford: Oxford University Press; 1998. p. 50-73.

14. Pardini $R$, Matsudo $S$, Matsudo V, Araújo T, Andrade E, Braggion $G$, et al Validation of the International Physical Activity Questionnaire (IPAQ): Pilot study in Brazilian young adults. Med Sci Sports Exerc. 1997;29(6):s5-9.

15. Miller MR, Hankinson J, Brusasco V, Burgos F, Casaburi R. Standardisation of spirometry. Eur Respir J. 2005;26(2):319-38.

16. Moreira LD, Fronza FC, Dos Santos RN, Zach PL, Kunii IS, Hayashi LF, et al. The benefits of a high-intensity aquatic exercise program (HydrOS) for bone metabolism and bone mass of postmenopausal women. J Bone Miner Metab. 2014;32(4):411-9.

17. Sociedade Brasileira de Pneumologia e Tisiologia. I Consenso Brasileiro de Espirometria. J Pneumol. 1996;22(3):125-9.

18. Canto-Costa MH1, Kunii I, Hauache OM. Body fat and cholecalciferol supplementation in elderly homebound individuals. Braz J Med Biol Res. 2006;39(1):91-8.

19. Persson LJ, Aanerud M, Hiemstra PS, Michelsen AE, Ueland T, Hardie JA, et al. Vitamin D, vitamin D binding protein, and 
longitudinal outcomes in COPD. Chalmers JD, ed. PLoS ONE. 2015;10(3):e0121622.

20. Majak P, Olszowiec-Chlebna M, Smejda K, Stelmach I. Vitamin D supplementation in children may prevent asthma exacerbation triggered by acute respiratory infection. J Allergy Clin Immunol. 2011;127(5):1294-6.

21. Rezk NASA, Aly NYA, Hewidy AAH. Effect of vitamin D replacement in chronic obstructive pulmonary disease patients with vitamin D deficiency. Egyptian Journal of Chest Diseases and Tuberculosis. 2015;64(2):353-7.

22. Wacker M, Holick MF. Vitamin D - Effects on skeletal and extraskeletal health and the need for supplementation. Nutrients. 2013;5(1):111-48.

23. Bergman P, Lindh ÅU, Björkhem-Bergman L, Lindh JD. Vitamin D and respiratory tract infections: a systematic review and meta-analysis of randomized controlled trials. PLoS One. 2013;8(6):e65835.

24. Gröber U, Reichrath J, Holick MF. Live Longer with Vitamin D? Nutrients. 2015;7(3):1871-80.

25. Yao TC, Tu YL, Chang SW, Tsai HJ, Gu PW, Ning HC, et al. Serum 25-hydroxyvitamin $D$ levels in relation to lung function and exhaled nitric oxide in children. J Pediatr. 2014;165(6):1098-1103.e1.

26. Hansdottir S, Monick MM, Hinde SL, Lovan N, Look DC, Hunninghake GW. Respiratory epithelial cells convert inactive vitamin $\mathrm{D}$ to its active form: potential effects on host defense. J Immunol. 2008;181(10):7090-9.

27. Song $\mathrm{Y}$, $\mathrm{Qi} \mathrm{H}, \mathrm{Wu} \mathrm{C}$. Effect of 1,25-(OH)2D3 (a vitamin $\mathrm{D}$ analogue) on passively sensitized human airway smooth muscle cells. Respirology. 2007;12:486-94.
28. Zosky GR, Berry LJ, Elliot JG, James AL, Gorman S, Hart PH. Vitamin $D$ deficiency causes deficits in lung function and alters lung structure. Am J Respir Crit Care Med. 2011;183(10):1336-43.

29. Berry DJ, Hesketh K, Power C, Hyppönen E. Vitamin D status has a linear association with seasonal infections and lung function in British adults. Br J Nutr. 2011;106(9):1433-40.

30. van Schoor NM, de Jongh RT, Daniels JMA, Heymans MW, Deeg DJH, Lips P. Peak expiratory flow rate shows a gender-specific association with vitamin D deficiency. J Clin Endocrinol Metab. 2012;97:2164-71.

31. Finklea JD, Grossmann RE, Tangpricha V. Vitamin D and chronic lung disease: a review of molecular mechanisms and clinical studies. Adv Nutr. 2011;2:244-53; PMID:22332056.

32. Dolhnikoff M, Bernardi FDC, Saldiva PHN. Estrutura morfológica e funcional dos pulmões. In: Carvalho CRR, Rocha e Silva M (Orgs.). Fisiopatologia respiratória. Série Fisiopatologia Clínica. São Paulo: Atheneu, 2005. p. 3-16.

33. Yurt M, Liu J, Sakurai R, Gong M, Husain SM, Siddiqui MA, et al. Vitamin D supplementation blocks pulmonary structural and functional changes in a rat model of perinatal vitamin D deficiency. Am J Physiol Lung Cell Mol Physiol. 2014;307(11):L859-67.

34. Ide MR, Belini MA, Caromano FA. Effects of an aquatic versus non-aquatic respiratory exercise program on the respiratory muscle strength in healthy aged persons. Clinics (Sao Paulo). 2005;60(2):151-8.

35. Pendergast DR, Lundgren CE. The underwater environment: cardiopulmonary, thermal, and energetic demands. J Appl Physiol (1985). 2009;106(1):276-83. 